\title{
ARTIVIDADES EM SALA DE AULA
}

A AUTORA

Ruth Ribas Itacarambi

Professora pesquisadora da Escola do Futuro - USP. Doutora pela Faculdade de

Educação da USP.

\section{ATIVIDADES COM COMUNICAÇÃO \& EDUCAÇÃO N. ${ }^{\circ} 27$}

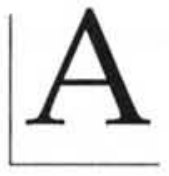

educação contribui para o desenvolvimento humano, na medida em que visa à realização do ser humano enquanto tal e não como meio de produção. A educação básica para todos deve englobar todos os conhecimentos necessários para que os jovens possam ter acesso aos demais níveis de formação. Assim, é preciso insistir no papel formador do ensino das diferentes áreas do conhecimento, despertando a curiosidade de meninos e meninas, desenvolvendo o seu sentido de observação e as atitudes de tipo experimental. E, na perspectiva da educação continuada, dar a todos os meios de modelar, livremente, a sua vida e de participar na evolução da sociedade, que corresponde a ter acesso a um conjunto de conhecimentos e de competências indispensáveis para o desenvolvimento humano.

Segundo as recomendações de Dacar ${ }^{1}$, Comissão da UNESCO, a formação de competências é sugerida a partir de algumas estratégias, entre as quais ressaltamos: diversificar as ofertas educativas diferenciando os conteúdos a fim de escapar ao modelo único, fonte de competição e de frustração, e diferenciar os tipos de percursos educativos, como por exemplo, utilizar os meios de comunicação tornando a escola mais atrativa.

É nesta perspectiva que propomos as atividades com os artigos desta edição, tornar a escola mais atrativa e quem sabe diminuir a exclusão social. A primeira atividade tem como tema gerador o artigo de Kaplún, Material educativo: a experiência de aprendizado. A atividade está direcionada, especialmente, aos profissionais de educação das várias áreas do conhecimento e/ou àqueles que trabalham com metodologia do ensino e didática. $\mathrm{O}$ artigo trata da construção das mensagens educativas a partir de três eixos: o eixo conceitual, o pedagógico e o comunicacional.

1. Fonte: Rapport de la deuxième sesssion de la comission (Dacar, 18-21 de setembro de 1993). Relatório para a Unesco da Comissão Internacional sobre Educaçâo para o século XXI. 
A segunda atividade tem como tema gerador Formas de ver e formas de atuar. Este tema surgiu do artigo de Magalhães A inter-relação entre criança e TV e do artigo de Christofoletti Ética e Cinema: notas sobre uma experiência didática. $\mathrm{O}$ primeiro artigo trata das relações entre as crianças e a TV e de sua capacidade de interação - formas de ver. O segundo artigo trata dos procedimentos e das condutas éticas dos profissionais do jornalismo - formas de atuar.

\section{PRIMEIRA ATIVIDADE: Material educativo}

A atividade tem como objetivo discutir no processo de ensino-aprendizagem, inicialmente, o significado dos conteúdos, sua seleção e organização; em seguida, a quem se destinam os conteúdos - seres humanos e, finalmente, quais são os possíveis meios entre os conteúdos e os sujeitos. E na discussão dos meios ter presente a construção do processo interacional comunicativo-educativo e a articulação transdisciplinar.

Os temas a serem desenvolvidos são:

- O que é um material (ou mensagem) educativo?

- Conteúdos: a aventura da criação

- Itinerários e jogos

- A articulação transdisciplinar

O primeiro tema pode ser trabalhado a partir da leitura do artigo: Material educativo: a experiência de aprendizado, de Kaplún. Como já foi dito, a atividade é dirigida, em especial, aos profissionais que trabalham com a educação e/ou estudantes que se dedicarão à educação nas várias áreas do conhecimento. Assim, propomos para este público a leitura crítica do artigo, ou seja, cada leitor deverá registrar os pontos de concordâncias e de discordâncias, as dúvidas e sua opinião pessoal sobre o assunto. O professor orientador desta atividade deverá, então, fazer um painel dos pontos levantados, registrando-os no quadro de giz e/ou cartazes e em seguida abrir a discussão a partir das seguintes questões:

- O que é um material (ou mensagem) educativo?

- O livro didático é um material educativo?

-As obras literárias, cinematográficas, plásticas, os vídeos, jornais são materiais educativos?

- Qual é a importância do contexto, na visão do autor?

Após esta discussão, o professor orientador poderá propor a leitura coletiva do item: $O$ que é um material (ou mensagem) educativo? do artigo, fazendo o fechamento do painel.

Continuamos o trabalho agora com o segundo tema: Conteúdos, a aventura da criação. $\mathrm{O}$ professor orientador poderá propor a formação de pequenos grupos para discutir as seguintes questões: como selecionar os materiais educativos? quais os cuidados necessários para a produção de um material educativo?

Para subsidiar a discussão os grupos poderão reler o artigo, em particular os itens: Conteúdos: o eixo conceitual e Itinerários: o eixo pedagógico. Na síntese dos grupos o professor orientador deverá dar especial atenção à formação do significado das "idéias construtoras" e de conflito conceitual, noções abordadas pelo autor.

Sobre as idéias construtoras, o autor oferece alguns percursos que os grupos poderão aproveitar para refletir sobre o 
eixo pedagógico apresentado no início do artigo. Como exercício sugerimos que os grupos façam um levantamento de opinião na escola e/ou em outro ambiente de trabalho sobre alguma questão pertinente ao conteúdo que será trabalhado. Nesta atividade a pergunta que escolhemos é:

- Qual a importância da informática no seu ambiente de trabalho?

As respostas poderão ser organizadas pelos grupos de modo a identificar as idéias prévias dos sujeitos consultados, verificando se é possível agrupá-las segundo os dois eixos propostos pelo autor: os que consideram a informática uma varinha mágica e os que a consideram inútil.

Com as respostas, o desafio para os grupos é pedagógico, partir dos conhecimentos prévios, criar um conflito conceitual e desconstruir algumas das concepções iniciais sem destruí-las, mas como material de base para realizar nova reconstrução. Pois, segundo o autor, o eixo pedagógico expressa o caminho que estamos convidando alguém a percorrer, que pessoas estamos convidando e onde estavam essas pessoas antes de partir. Como apoio para este desafio sugerimos a leitura do item: Jogos: o eixo comunicacional, principalmente quando escreve sobre a capacidade de brincar, utilizando jogos de palavras ou de imagens, inventar histórias, criar personagens, inventar paisagens visuais ou sonoras, entre outras. Assim os grupos serão convidados a serem criativos e elaborar situações didáticas para reconstruir as idéias, no caso a importância da informática no mundo contemporâneo: vantagens e desvantagens.

A produção deste material leva em conta que o saber passa por uma articulação transdisciplinar.
Estas situações poderão ser sintetizadas numa página da Internet, reforçando a informática como meio de comunicação, uma vez que foi objeto do levantamento, ou na elaboração de um artigo para jornal/mural do local de trabalho.

\section{SEGUNDA ATIVIDADE: \\ Formas de ver e formas de atuar}

A atividade tem como um dos objetivos fazer uma reflexão sobre a singularidade das crianças e um modelo que tente entender a inter-relação entre criança e televisão tendo como ponto de partida o artigo de Magalhães $A$ inter-relação entre criança e TV e como apoio a Videografia desta edição. O outro objetivo desta atividade é estudar a utilização de um recurso tecnológico - fitas de vídeo - no ambiente da sala de aula como recurso para uma reflexão sobre os valores éticos profissionais, abordado no artigo de Christofoletti Ética e cinema: notas sobre uma experiência didática e o artigo de Meditsch, Filosofia de Paulo Freire e práticas cognitivas no jornalismo.

Os temas a serem desenvolvidos são:

- A TV educa seus telespectadores?

- Quais as diferenças entre a escola e a televisão?

- Os diferentes olhares para a televisão

- Os valores éticos veiculados pelos meios de comunicação TV, vídeo e cinema.

Esta atividade é adequada para os alunos do ensino básico: ensino fundamental e médio. $O$ professor poderá apresentar para o quadro 1 do artigo de Magalhães $A$ interrelação entre criança e TV e pedir para que leiam e façam uma reflexão individual tentando verificar com qual dos per- 
sonagens eles mais se identificam: Juninho ou Lúcia. O professor, coletando estas informações individuais, poderá ter um breve perfil dos seus alunos enquanto telespectadores. A preocupação, neste momento, é verificar se os alunos não estão se identificando com o Juninho, por exemplo, por serem meninos e vice-versa. Em seguida, o professor propõe que os alunos, em pequenos grupos, escolham um programa infantil, por exemplo: Castelo Rá-Tim-Bum, na TV Cultura ou Xuxa no Mundo da Imaginação e/ou Sítio do Picapau Amarelo na TV Globo etc., anotem as informações que estão recebendo enquanto telespectadores e façam, nos grupos, a síntese, utilizando uma tabela. $\mathrm{Na}$ primeira coluna registrarão as informações que já sabiam e na segunda coluna o que aprenderam.

$\mathrm{Na}$ sala de aula o professor poderá fazer uma única tabela para cada programa assistido e discutir com seus alunos a questão de que a televisão "educa" os seus telespectadores, só que, nem sempre, em benefício do próprio e da melhoria da sociedade onde vive e que um mesmo telespectador tem diferentes olhares para a televisão. Para subsidiar o professor nesta discussão sugerimos a leitura complementar do artigo de Magalhães e que se detenha em especial nas considerações sobre a obra de Bernard Charlot e sobre a escola como não sendo tão diferente da TV, pois ambas procuram a formação de seu público.

Se os alunos forem do $1^{\circ}$ ciclo do Ensino Fundamental, o professor poderá exibir uma fita de vídeo sobre desenhos animados, na videografia desta edição são apresentadas sugestões e algumas permitem trabalhar valores éticos a partir de uma linguagem simples.
Agora, na perspectiva da melhoria da sociedade, o professor poderá selecionar uma fita de vídeo, em que alguns personagens se deparam com situações em que os valores éticos são colocados em xeque, suas condutas são avaliadas por terceiros ou suas ações podem interferir nos acontecimentos. A proposta é seguir o roteiro do artigo de Christofoletti Ética e Cinema: notas sobre uma experiência didática, ou seja, os alunos deverão anotar:

Qual é o dilema ético em questão?

Como agem os personagens nesta situação? Esta foi a melhor saída?

E se fosse você? De que forma agiria?

$\mathrm{O}$ artigo apresenta algumas sugestões de títulos que, embora dirigidos aos jornalistas, podem ser analisados pelos profissionais em geral, entre eles os da educação. Os alunos do ensino médio que estão indo ou já estão no mercado de trabalho poderão tirar grande proveito pessoal desta análise. E para aqueles que manifestarem vontade de saber um pouco mais da atividade jornalística, o professor poderá sugerir a leitura do artigo de Meditsch, Filosofia de Paulo Freire e práticas cognitivas no jornalismo.

A idéia é, após a exibição do vídeo, os alunos fazerem um debate em pequenos grupos sobre suas anotações e escolherem um relator para apresentar suas considerações para o grupo classe. Então, o professor e os relatores preparam uma síntese das considerações, que poderá se transformar num artigo para o jornal da escola ou numa página na Internet, contendo a resenha do filme e a análise crítica. Lembramos que ao redigir o artigo os alunos e o professor deverão estar atentos às questões éticas que acabaram de discutir. Assim 
o artigo é um exercício de condutas éticas. Como apoio para a síntese o professor poderá voltar aos artigos citados de Christofoletti e de Meditsch.

No artigo de Meditsch o professor encontrará algumas reflexões de Paulo Freire sobre a atividade jornalística. Su-

Resumo: A autora propōe duas atividades didáticas para tornarem a escola mais atrativa e quem sabe diminuir a exclusão social, a partir da leitura dos seguintes artigos deste número de Comunicação \& Educação: $M a-$ terial educativo: a experiência de aprendizado; $A$ inter-relação entre criança e TV; Ética e cinema: notas de uma experiência didática; Filosofia de Paulo Freire e práticas cognitivas no Jornalismo. O objetivo é convidar os alunos a serem criativos e a elaborarem situaçōes didáticas para reconstruir as idéias usando a informática como meio de comunicação; e fazer um exercício de condutas éticas.

Palavras-chave: Comunicação \& Educação, exclusão social, material educativo, ética, jornalismo gerimos trazer para os alunos a seguinte: "Os sonhos são projetos pelos quais se luta (...). Possivelmente, um dos saberes fundamentais mais requeridos para o exercício de um tal testemunho é o que se expressa na certeza de que mudar é difícil mas é possivel" 2 .

(Activities with Comunicação \& Educação No. 27) Abstract: The author proposes teaching activities to make school more attractive and to possibly reduce social exclusion based on the reading of the following articles in this edition of Comunicação \& Educação: Educational material: the experience of learning, The interrelation between the child and the TV; Ethics and cinema: notes on a teaching experience; Paulo Freire Philosophy and cognitive practices in Journalism. The goal is to invite the students to be creative and to elaborate teaching situations to reconstruct ideas using information technology as a means of communication; and performing an exercise of ethical behavior.

Key words: Comunicação \& Educação, social exclusion, educational material, ethics, journalism

2. FREIRE, P. Pedagogia da Indignação. São Paulo: Editora UNESP. 2000, p. 55. 